\title{
Are primary care physicians, public and private sector specialists substitutes or complements? Evidence from a simultaneous equations model for count data
}

\author{
Vincenzo Atella ${ }^{\mathrm{a}, *}$, Partha Deb $^{\mathrm{b}}$ \\ a CEIS-SEFEMEQ, University of Rome Tor Vergata, Rome, Italy \\ ${ }^{\mathrm{b}}$ Department of Economics, Hunter College, City University of New York, New York, USA \\ Received 20 May 2005; received in revised form 3 June 2007; accepted 18 October 2007 \\ Available online 18 January 2008
}

\begin{abstract}
In this paper, we examine the relationships between health care visits to general practitioners, public and private sector specialists using data from Italy, which has a mixed public-private health care system. We develop a simultaneous equations model that allows for the discreteness of measures of utilization and estimate this model using maximum simulated likelihood. Once common unobserved heterogeneity is properly accounted for, general practitioners, public and private specialists are found to be substitute sources of medical care. In contrast, a naive model finds they are complements.
\end{abstract}

(C) 2007 Elsevier B.V. All rights reserved.

JEL classification: C15; C35; H42; I11

Keywords: Negative binomial; Endogeneity; Demand for health care

\section{Introduction}

In most developed countries of the world, health care is predominantly financed by the state and is often provided within the public sector. Yet, in these systems, provision of health care services in the private sector has a significant role in spite of heavily subsidized, and in many cases free, public provision. In many such countries, in fact, the role of the private sector is increasing due to increasing coverage through private health insurance plans and due to increasing out of pocket payments in the public sector.

The existence of mixed public-private systems raise numerous issues of policy relevance. Should the government encourage or discourage private provision of health care services? It is sometimes argued that private services may undermine the public system, so that the government ought to discourage any private alternative. For example, it is possible that an increase in the use of private services may be accompanied by a decrease in the willingness to pay taxes for the public sector, thus undermining quality in the public sector. One could however also argue, on efficiency and/or equity grounds, that those who choose to receive care in the private sector should be publicly subsidized because they take the pressure off public systems with binding capacity

\footnotetext{
* Corresponding author. Tel.: +3906 72595635; fax: +39062020687.

E-mail address: atella@uniroma2.it (V. Atella).
} 
constraints (Cullis and Jones, 1985). In addition, there are implications for the labor market since labor in the public sector is also employed in the private sector, often simultaneously, in such systems. Each of these implications is conditioned on the nature of relationships among types of services supplied by public and private sector providers.

The aim of this paper is to investigate one aspect of the relationships between private and public sector provision of health care services in mixed public-private systems using an econometric model that allows for substitution and/or complementarities between the use of primary care physicians, who are all employed in the public sector, specialists who are employed in the public sector and specialists who work in the private sector.

There is considerable theoretical literature on public-private sector interactions: Stiglitz (1974), Ireland (1990) and Besley and Coate (1991) describe theoretical models in which individuals can purchase a private sector alternative which allows them to opt out of the public sector, while Epple and Romano (1996) and Gouveia (1996) present models where individuals can supplement their public sector allocations. In either case, the implications of these models suggest substitutability between public and private sector alternatives. However, there is relatively little empirical evidence on the existence and nature of possible substitutions. For the USA, Cutler and Gruber (1996) show that the availability of Medicaid (a public insurance plan for low income individuals) diminishes the incentive of low income individuals to purchase private insurance. For the UK, Besley et al. (1999) show that longer waiting lists for NHS treatment are associated with greater purchases of private health insurance while Martin and Smith (1998) use ward level data and find an effect of waiting lists on demand for NHS elective surgery.

Closer to our research in terms of empirical strategy are the papers by Propper (2000), Fabbri and Monfardini (2002) and Atella et al. (2004). Although Propper does not distinguish between primary care physicians and specialists, her results show that the patterns of association between public and private sector use is quite complex. Private use in the past is more likely to lead to current private use than public use, but private service use in the past is also associated with current public use. Fabbri and Monfardini (2002) use count models to describe the relationships between individual characteristics and the use of public and private specialists in Italy. They find that use of private and public specialists are driven by different processes. Atella et al. (2004) describe the determinants of access to primary care and specialist providers of care in the public and private sectors in Italy with an emphasis on the role of income, demonstrating differential affects of income on access to public and private sector services. However, none of these papers model possible substitutions or complementarities between the use of private and public sector providers.

In contrast to these previous studies, we introduce an econometric methodology that explicitly models possible substitutions or complementarities between the use of primary care physicians (PCPs), public and private specialists. Our framework allows for the discreteness of measures of utilization (counts with high frequencies of zeros) in a simultaneous equations system. Simultaneity arises because the use of a particular type of physician is assumed to affect the use of other types of physicians and because of the presence of unobserved heterogeneity arising from latent health status, patient preferences and patients preferences between PCPs, public and private specialists. We apply maximum simulated likelihood (MSL) techniques to estimate a system of nonlinear equations. Simulation is used to evaluate integral expressions in the likelihood function of the model, as no closed form solutions exist.

The paper also contributes to the literature on econometric analysis of count data. Although there is a large literature in this area (Cameron and Trivedi, 1998), relatively little deals with multivariate counts. These have been studied in simplified cases with restricted correlation structures by Jung and Winkelmann (1993) and Gurmu and Elder (2000). More recently, Munkin and Trivedi (1999) use maximum simulated likelihood methods and Chib and Winkelmann (2001) use Bayesian methods to model correlated counts in a flexible fashion. To date, however, there appears to be no applications of these multivariate count models when they form a system of simultaneous equations, rather than a seemingly unrelated system of equations as in Munkin and Trivedi (1999) and Chib and Winkelmann (2001).

We find that, once endogeneity is properly accounted for, PCPs, public and private specialists are substitute sources of medical care. PCPs indeed have significant roles as gatekeepers to specialist care and that public and private specialists are substitutes. This is in contrast to the results from a naive model, where PCPs, public and private specialists appear to be complements.

The remainder of the paper is organized as follows. Section 2 presents background on the Italian National health system. Section 3 discusses the theoretical model. Section 4 describes the data set. Section 5 discusses the econometric strategy adopted and presents the results of the empirical analysis. Finally some conclusions are drawn in Section 6. 


\section{The Italian health care system}

Since 1978, the Italian health system has been regulated by and administered through the "Servizo Sanitario Nazionale" (SSN), a National Health Service Agency. This public system is based on four main principles: universal coverage, provision of a full range of health services, participation of citizens in management and organizational pluralism (state, regions and local health authorities). The system is organized along three levels: national, regional and local. The national level is responsible for designing the national health plans with the aim of ensuring general health objectives and interventions. It is then the responsibility of the regional governments to achieve the objectives posed by the national health plan. Authorities at the regional level organize delivery of services to the population through a network of local health care organizations, public hospitals and accredited private hospitals. They plan health care activities and organize local supply according to estimates of local-population needs. Moreover, they have the responsibility to guarantee quality, appropriateness and efficiency of the services provided. Local health care providers are obliged to guarantee equal access, efficacy of preventive, curative and rehabilitation interventions and efficiency in the distribution of services. They are also responsible for financial balance between funding provided by regions and local expenditures on health care services.

The system has undergone several reforms over the years to solve issues linked to its management and financing. Until the late 1990s, the system was financed through compulsory worker contributions (around 50\%), general taxation and borrowing (42\%), patient copayments (4\%) and some other minor revenue sources. Today, the NHS is financed mainly through a regional tax on productive activities. Regions can use also other funds to finance their health services and this has given rise to increase copayments required for services received by patients. Copayments depend on the income, age and health conditions of patients and are required for drugs, ambulatory treatment, specialist care and for some diagnostic and laboratory tests. Private financing has been playing an increasing role over time. Today, about $70 \%$ of expenditures are publicly financed, with the remaining $30 \%$ financed by private expenditures, of which only $10 \%$ is covered by private health insurance and company health plans. ${ }^{1}$

In providing health care services the SSN uses a wide array of providers: hospitals with different forms of ownership (directly managed, public hospital trusts; public and private teaching hospitals; public and private research hospitals; non-profit hospitals; for profit hospitals), primary care physicians (PCPs) who are employed by the SSN, public and private ambulatory care facilities (specialists offices and diagnostic testing clinics), public and private rehabilitation facilities and private community nurses. Physician services in the public system are provided by both PCPs and by specialists employed in the public system and accessed by patients through referrals from PCPs. PCPs are paid on a capitation basis. In general, they can serve at the most 1500 patients and receive a salary that is based on the number of patients they serve. Patients do not pay for visits to PCPs, and there is no limit to the number of visits they can have. For each visit to a specialist in the public system, patients pay a fee (about €35) but access is regulated by PCPs. ${ }^{2}$ In general, patients must use providers in the local health authority in which they reside and they must have referrals from their PCPs for most specialized or diagnostic forms of care. However, within a local health area, patients can change their PCP as they wish, as long as the physician has some slack capacity.

Patients may also seek care from specialists who work in the private sector. These providers are not regulated by the public system and referrals are not required, but fees for visits to such providers are market-based and, therefore, are much higher than those for public sector specialists.

\section{Econometric methods}

Based on the institutional characteristics of the SSN described above, we envision most patients engaging in a sequential decision-making process. Typically, there are no queues to receive care from PCPs and the monetary price of such care is zero, so we assume that health care utilization decisions along this dimension are made first. Care from public specialists can only be received with a referral from a PCP, so this is the decision a patient would make next. Finally, we assume that individuals would opt to receive care from private specialists if they received (or

\footnotetext{
${ }^{1}$ Note that this low share of patients with private health insurance exists despite a relatively high share of private health care expenditures (which grew up, in particular, after the health reforms that occurred between 1992 and 1994).

2 All the information reported on the structure of the Italian SSN refer to the years 1999-2000, the period closest to the data used in our empirical analysis.
} 
perceived receiving) low-quality care from PCPs and/or public specialists or if the waiting times to receive care from public specialists was sufficiently high. We begin with an equation for the number of visits to a PCP. As they are the gatekeepers to specialist care received in the public sector, it stands to reason that the number of visits to public specialists is determined, at least in part, by the number of PCP visits, a feature embodied in the equation for number of visits to public specialists. Patients may bypass the public system entirely in visiting private sector specialists, or may choose to use them as substitutes for only public sector specialists, so we model the number of visits to private specialists as a function of PCP and public specialist visits. Implications of this particular decision-process are discussed below.

\subsection{The model}

Formally, let $y_{j i}$ denote the counts of observed values of utilization, $y_{j i}$ for the $j$ th type of physician, $j=1$ (PCP), $j=2$ (public specialist) and $j=3$ (private specialist). Let $\mathbf{z}_{j i}$ denote physician-type and individual-specific observed exogenous variables. Then, following the systemic considerations described above, we assume that the conditional mean of public specialist visits depends on the number of PCP visits and the conditional mean of private specialist visits depends on the numbers of PCP and public specialist visits. In a more formal way, we have

$$
\begin{aligned}
& \mu_{1 i}=\exp \left(\mathbf{z}_{1 i}^{\prime} \beta_{1}+l_{1 i}\right) \\
& \mu_{2 i}=\exp \left(y_{1 i} \gamma_{21}+\mathbf{z}_{2 i}^{\prime} \beta_{2}+l_{2 i}\right) \\
& \mu_{3 i}=\exp \left(y_{1 i} \gamma_{31}+y_{2 i} \gamma_{32}+\mathbf{z}_{3 i}^{\prime} \beta_{3}+l_{3 i}\right)
\end{aligned}
$$

where the $l_{j i}$ denote latent variables. To the extent that some physician-type and individual characteristics are unobserved, they are absorbed into the latent variables $l_{j i}$. Among individual characteristics, unobserved components of individual and family health history, attitudes towards health risks, lifestyle choices, individual perceptions of health events, etc., are likely to be important. It is also reasonable to expect the $l_{j i}$ to be correlated with each other and this is the source of simultaneous equations bias if not taken into account in estimation.

We use a common factor specification to introduce correlation between the latent variables:

$$
l_{1 i}=f_{1 i}, \quad l_{2 i}=\phi_{21} f_{1 i}+f_{2 i}, \quad l_{3 i}=\phi_{31} f_{1 i}+\phi_{32} f_{2 i}
$$

where $f_{1 i}$ and $f_{2 i}$ are independent latent factors, whose distributions are described below. Although $f_{1 i}$ and $f_{2 i}$ are independent, they imply covariances of $\phi_{21}$ between $l_{1 i}$ and $l_{2 i}$, of $\phi_{31}$ between $l_{1 i}$ and $l_{3 i}$ and $\left(\phi_{21} \phi_{31}+\phi_{32}\right)$ between $l_{2 i}$ and $l_{3 i}$, which is a completely general specification of covariances between $l_{1 i}, l_{2 i}$ and $l_{3 i}$.

Issues of model identification arise due to the introduction of endogenous variables as regressors in Eqs. (2) and (3). The model is formally identified by its nonlinear functional forms, but for more robust identification we introduce exclusion restrictions. These are described in greater detail in Section 4 below.

Our model is recursive because the number of GP visits affects the number of public and private specialists but the reverse is not true. In addition, the number of visits to public specialists affects the number of visits to private specialists but the reverse is not true. Although, this recursive specification is consistent with the institutional structure of health care provision in Italy, we recognize that "reality" may be somewhat different than our "ideal" structure. Recursivity is a sufficient condition for model coherency in simultaneous equations models for count data. Other nonlinear systems of equations also require coherency restrictions. For example, in the probit system, recursivity is a necessary condition for coherency. In the Tobit system, Amemiya (1974) showed that the necessary condition for coherency requires that all principal minors of $(I-G)$ be positive, where $G$ is the matrix of parameters on endogenous regressors in the system. Windmeijer and Santos Silva (1997) derived the coherency conditions in a bivariate count-data system. The necessary conditions for coherency are unknown in a trivariate count-data system such as ours.

Other recursive structures may be specified, but these would have even less connection with the institutional setting. In order to gauge the practical importance of the coherency restrictions, we attempted to estimate a fully simultaneous model with no coherency restrictions. While all of our runs of the recursive model took 10-15 iterations and $6-10 \mathrm{~h}$ of CPU time to converge, this model failed to converge after 41 iterations and almost 4 days of CPU time.

The choice of functional form or link for the endogenous variables on the right hand sides of Eqs. (2) and (3) is also a potential issue. We have used an identity link, but a logarithmic link might be more consistent with the exponential mean specifications we have chosen for the dependent variables. Unfortunately, $\log \left(y_{j i}\right)$ contains many zeros for each $j$ 
so an additional adjustment would be required. Instead of making an ad hoc adjustment to $\log \left(y_{j i}\right)$, we actually estimated models with Box-Cox links, i.e., $\left(y_{j i}^{\lambda}-1\right) / \lambda$, for values of $\lambda$ from 0.1 to 1 , by increments of $\lambda$. Although, the optimal value of $\lambda$ in the Box-Cox transformation was 0.7 , our results, in terms of marginal effects of the parameters on these variables, were extremely close to those obtained with $\lambda=1$. Therefore, for ease of interpretation, in what follows we present and discuss only the results obtained with $\lambda=1$.

Finally, each of the dependent variables has a large proportion of zeros prompting the possibility of estimating systems of zero-inflated or two-part negative binomial models. We attempted estimation of such models in the early stages of our analysis but such models were numerically very unstable, so we did not pursue them further. Both models suffer from the curse of dimensionality and, in addition, zero-inflated models have difficult-to-optimize likelihood functions unless exclusion restrictions are imposed. Therefore, although these models would provide a richer description of the data generating process, we opted for the "simpler" system of negative binomial regressions.

\subsection{Estimation}

Conditional on the latent factors $f_{1 i}$ and $f_{2 i}$ and observed covariates, the joint density of the three types of medical care or the likelihood contribution of an individual can be written as

$$
L_{i}\left(y_{1 i}, y_{2 i}, y_{3 i} \mid \mathbf{z}_{1 i}, \mathbf{z}_{2 i}, \mathbf{z}_{3 i} ; f_{1 i}, f_{2 i}\right)=\mathbf{f}_{1}\left(y_{1 i} \mid \mathbf{z}_{1 i} ; f_{1 i}\right) \times \mathbf{f}_{2}\left(y_{2 i} \mid \mathbf{z}_{2 i} ; f_{1 i}, f_{2 i}\right) \times \mathbf{f}_{3}\left(y_{3 i} \mid y_{1 i}, y_{2 i}, \mathbf{z}_{3 i} ; f_{1 i}, f_{2 i}\right)
$$

i.e., as a product of a marginal and two conditional densities. Because the outcomes of interest are nonnegative integer values, we assume that each of the counts follows a negative binomial-2 distribution with mean $\mu_{j i}$ and scale $\alpha_{j i}$ such that

$$
\mathbf{f}_{j}\left(y_{j i} \mid \mathbf{X}_{j i} ; \mu_{j i}, \alpha_{j} ; f_{1 i}, f_{2 i}\right)=\frac{\Gamma\left(y_{j i}+\psi_{j}\right)}{\Gamma\left(\psi_{j}\right) \Gamma\left(y_{j i}+1\right)}\left(\frac{\psi_{j}}{\mu_{j i}+\psi_{j}}\right)^{\psi}\left(\frac{\mu_{j i}}{\mu_{j i}+\psi_{j}}\right)^{y_{j i}}
$$

where $\psi_{j} \equiv 1 / \alpha_{j}\left(\alpha_{j}>0\right)$ and $\mathbf{X}_{1 i}=\left[\mathbf{z}_{1 i}\right], \mathbf{X}_{2 i}=\left[\mathbf{y}_{1 i}, \mathbf{z}_{2 i}\right]$ and $\mathbf{X}_{3 i}=\left[y_{1 i}, y_{2 i}, \mathbf{z}_{3 i}\right]$. The negative binomial density is a standard choice for counts that display overdispersion and is a popular choice in empirical studies of medical care visits (Cameron and Trivedi, 1998).

If $f_{1 i}$ and $f_{2 i}$ were known, estimation of the parameters of (5) could proceed by maximum likelihood. However, because $f_{1 i}$ and $f_{2 i}$ are latent, some distributional assumptions on these factors are needed to identify the parameters of the model. We assume that $f_{1 i}$ and $f_{2 i}$ are drawn from i.i.d. unit normal distributions with densities denoted by $\mathbf{n}_{k}$, $k=1$ and 2 . The likelihood for an individual conditional only on observables is obtained by integrating out the latent factors $f_{1 i}$ and $f_{2 i}$ and the integration can be performed numerically rather than analytically using the approximation in the second line of the equation given below:

$$
\begin{aligned}
L_{i}\left(y_{1 i}, y_{2 i}, y_{3 i} \mid \mathbf{Z}_{i} ; f_{1 i}, f_{2 i}\right) & =\int \prod_{j=1}^{3} \mathbf{f}_{j}\left(y_{j i} \mid \mathbf{Z}_{i} ; \mu_{j i}, \alpha_{j} ; f_{1 i}, f_{2 i}\right) \mathbf{n}_{1}\left(f_{1 i}\right) \mathbf{n}_{2}\left(f_{2 i}\right) \mathrm{d} f_{1 i} \mathrm{~d} f_{2 i} \\
& \approx \frac{1}{S} \sum_{s=1}^{S}\left\{\prod_{j=1}^{3} \mathbf{f}_{j}\left(y_{j i} \mid \mathbf{Z}_{i} ; \mu_{j i}, \alpha_{j} ; \tilde{f}_{1 i}, \tilde{f}_{2 i}\right)\right\}
\end{aligned}
$$

where $\tilde{f}_{1 i}$ and $\tilde{f}_{2 i}$ are random draws from $\mathbf{n}_{1}$ and $\mathbf{n}_{2}$. The maximum simulated likelihood (MSL) estimator involves maximizing this simulated likelihood (Gouriéroux and Monfort, 1996).

To speed up convergence of the simulated likelihood to the true likelihood, and to reduce simulation "chatter" efficiently, we use quasi-Monte Carlo draws and antithetic acceleration. The quasi-Monte Carlo draws are based on Halton sequences, which have desirable properties (Bhat, 2001; Train, 2003; Deb and Trivedi, 2006). We use 200 draws per observation in our study. Experimentation with different numbers of simulation draws yielded very similar estimates.

We maximize the simulated likelihood using a Newton-Raphson algorithm utilizing analytical gradients and Hessian. Post-convergence the variance of the MSL estimates is obtained using the Eicker-White sandwich formula with adjustments for clustering. Because our exclusionary variables are measured only at the region level, standard errors without clustering adjustments would normally overstate the precision of the estimates. Therefore, the standard errors 
we report are adjusted for clustering at the region level, 20 clusters in all. Note that information matrix and outer product formulae for standard errors are inappropriate because they do not take into account uncertainty due to simulation chatter (McFadden and Train, 2000). Marginal effects of covariates on the outcomes are calculated by simulation. We calculate marginal effects for dummy variables as discrete changes and for continuous variables using derivatives. These are evaluated at the sample means of all other covariates. Standard errors of the marginal effects are calculated using the delta method (Greene, 2003).

\section{Data}

The data used for the empirical analysis are from the ISTAT Multiscopo Survey (MS), conducted by Italian National Institute of Statistics in 1999-2000 (ISTAT, 2001). This survey is conducted every 5 years, with the aim of evaluating prevalence of chronic health conditions and the use of the health care services in the Italian population. In 1999-2000, 140,011 individuals in 52,332 households were surveyed. After eliminating individuals less than 15 years of age and a few observations with missing values, the sample used in this analysis has 109,349 observations. Children were not considered because the rules governing their access to physicians in the public sector are different from those governing adult access.

\subsection{Utilization of services}

Information on service utilization are obtained through a detailed questionnaire in which respondents are first asked if over the last 4 weeks they have visited a PCP or a specialist and, in the latter case, what kind of specialist (public or private). ${ }^{3}$ For positive responses, they are further asked to answer how many times they have visited PCPs, public specialists and private specialists. ${ }^{4}$

Summary statistics presented in Table 1 show that, in a given month, the average number of PCP visit per patient is 0.24 . In addition, the average number of visits to private specialists is about 0.14 , and this average goes down to about 0.10 in case of public specialists. It is interesting to note that public specialist use is lower than private specialist use, in spite of the fact that visits to private specialists are considerably more expensive. ${ }^{5}$

The sample means are small mainly because the percentage of zeros is high for each type of physician visit. Table 2 shows that, while $16 \%$ of individuals visited PCPs over a month, about $7 \%$ saw a public specialist while about $9 \%$ sought care from private specialists. The fact that more people sought care from private specialists than public specialists is indicative of the fact that PCPs act as gatekeepers to public specialist care, while private specialists can be seen without a visit to the PCP. The modal number of visits, among those who seek care, is one, but the distribution has a long tail in each case. Table 2 also reports the frequency distributions of specialist visits conditional on seeing a PCP at least once. The conditional frequencies of zero specialist visits are smaller than the unconditional ones, while the conditional frequencies of one or more visits are larger than the unconditional ones. These results suggest that PCP and specialist care might be complements if there were no issues of endogeneity. However, endogeneity is likely to be an important statistical issue.

\subsection{Exogenous covariates}

The covariates used in our study are typical of those used in previous studies on the determinants of medical care. In particular, the explanatory variables include health status, age, gender, education and income.

\footnotetext{
${ }^{3}$ As noted by a referee, the 4-week window of the reporting period is rather short (compared for example to the 12-month period used in the Europanel (ECHP)). This adds considerable noise to the measures of utilization and increases the proportions of zeros. In addition, we are less likely to observe information for complete episodes of care. For example, a patient may visit a specialist more than 4 weeks after being referred to one by a PCP, but this would be outside the 4-week recall window of the questionnaire and thus not be measured.

4 The exact phrasing of the questioner is the following: "Over the last four weeks, have you visited a. ..?". In case of positive answer the respondent is further asked: "Over the last four weeks, how many times have you visited a ...?".

${ }^{5}$ It is interesting to note also that according to the 1991 survey the values were 0.18 for PCPs, 0.06 for private specialists and 0.06 for public specialists. This clearly shows that in a decade the average number of physician visits has considerably increased, with private specialist visits having more than doubled.
} 
Table 1

Descriptive statistics

\begin{tabular}{|c|c|c|c|c|}
\hline Variables & Mean & S.D. & Min. & Max. \\
\hline \multicolumn{5}{|l|}{ Dependent variables } \\
\hline Primary care physician visits & 0.235 & 0.669 & 0.000 & 9.000 \\
\hline Public specialist visits & 0.096 & 0.431 & 0.000 & 11.000 \\
\hline Private specialist visits & 0.136 & 0.536 & 0.000 & 12.000 \\
\hline \multicolumn{5}{|l|}{ Independent variables } \\
\hline Fair health ${ }^{\mathrm{a}}$ & 0.362 & 0.481 & 0.000 & 1.000 \\
\hline Good health $^{\mathrm{a}}$ & 0.429 & 0.495 & 0.000 & 1.000 \\
\hline Very good health ${ }^{\mathrm{a}}$ & 0.130 & 0.336 & 0.000 & 1.000 \\
\hline Disabled $(1=$ disabled $)$ & 0.071 & 0.256 & 0.000 & 1.000 \\
\hline Exempt for health conditions ${ }^{b}$ & 0.103 & 0.305 & 0.000 & 1.000 \\
\hline Exempt for other reasons ${ }^{b}$ & 0.104 & 0.306 & 0.000 & 1.000 \\
\hline Gender $(1=$ male, $2=$ female $)$ & 1.530 & 0.499 & 1.000 & 2.000 \\
\hline Marital status $(1=$ married $)$ & 0.578 & 0.494 & 0.000 & 1.000 \\
\hline Level of education & 2.100 & 0.932 & 1.000 & 4.000 \\
\hline Age/10 & 4.600 & 1.897 & 1.500 & 10.500 \\
\hline $\mathrm{Age}^{2} / 100$ & 24.755 & 18.808 & 2.250 & 110.250 \\
\hline Household income $^{c}$ (in millions of liras) & 27.614 & 17.808 & 0.000 & 316.992 \\
\hline Poor household $(1=$ poor $)$ & 0.201 & 0.401 & 0.000 & 1.000 \\
\hline \multicolumn{5}{|l|}{ Excluded variables } \\
\hline Number of patients per $\mathrm{PCP} / 1000^{\mathrm{d}}$ & 1.166 & 0.385 & 1.014 & 2.941 \\
\hline Total/practicing specialists ${ }^{\mathrm{d}}$ & 1.099 & 0.073 & 1.005 & 1.341 \\
\hline
\end{tabular}

Note: Sample size is 109,349 .

${ }^{a}$ Health status is self-reported on a five-point scale from poor to excellent. Poor and fair health are combined into the omitted category.

b Exemption is from paying copayments for visits.

${ }^{c}$ Equivalized for size of household. In 1999-2000, the exchange rate was 1960 liras to US\$ 1.

${ }^{\mathrm{d}}$ Measured at the regional level.

Information on health status is provided by four dummy variables. The first reports the presence of a disability status, and it is obtained from a question that asks if the respondent is hampered in his/her daily activity by any physical or mental health problem, illness or disability. The dummy has been constructed in a way that the reference category is represented by individuals not hampered in their daily activity. The remaining three variables are constructed from a question that asks respondents to rate their health status by choosing between five categories of health conditions. Three dummy variables were constructed from these five categories: "very good health", "good health" and "fair health", with "poor or very poor health" being the reference category. The majority of the people declared they were in good or better health. In fact, $13 \%$ of respondents considered their health as "very good", $43 \%$ as "good", and $36.2 \%$ as

Table 2

Frequency (in \%) of physician visits by type

\begin{tabular}{|c|c|c|c|c|c|}
\hline \multirow[t]{2}{*}{ Visits } & \multirow[t]{2}{*}{ Primary care physician } & \multirow[t]{2}{*}{ Public specialist } & \multirow[t]{2}{*}{ Private specialist } & \multicolumn{2}{|c|}{ Conditional distribution $^{\mathrm{a}}$} \\
\hline & & & & Public specialist & Private specialist \\
\hline 0 & 84.42 & 93.12 & 90.98 & 86.87 & 88.03 \\
\hline 1 & 10.74 & 5.27 & 6.45 & 10.00 & 9.07 \\
\hline 2 & 3.17 & 1.04 & 1.52 & 2.08 & 1.18 \\
\hline 3 & 0.90 & 0.32 & 0.51 & 0.62 & 0.60 \\
\hline 4 & 0.54 & 0.13 & 0.34 & 0.20 & 0.26 \\
\hline 5 & 0.10 & 0.05 & 0.07 & 0.08 & 0.09 \\
\hline 6 & 0.05 & 0.02 & 0.05 & 0.05 & 0.06 \\
\hline 7 & 0.02 & 0.02 & 0.02 & 0.03 & 0.04 \\
\hline 8 & 0.05 & 0.02 & 0.03 & 0.04 & 0.02 \\
\hline 9+ & 0.02 & 0.01 & 0.02 & 0.03 & 0.03 \\
\hline
\end{tabular}

\footnotetext{
${ }^{a}$ Distribution is conditional on primary care physician $>0$.
} 
"fair". Previous research has shown that poor individuals have, on average, worse health status. Our results confirm this finding. People who reported in general to be in a "very poor" or "poor" health status were concentrated in the lower income quintiles.

Most individuals are required to make a copayment when visiting a public sector specialist. However, about $10 \%$ of the population is exempt from such copayments either because of illness or disability or because of other reasons (mainly poverty status).

The sample is almost equally divided into males and females. The average age of the population (after dropping all children below 15 years) under investigation is 46 years. About $58 \%$ of the sample are married, with the remaining being single, divorced, legally separated or widowed.

Educational characteristics are measured through a polychotomous variable with four categories going from the lowest for primary education to the highest for university degree. In preliminary work, we experimented with education specified using three dummy variables. However, we did not observe substantial nonlinearities, so in order to keep our model concise, we report results from a linear education specification. Respondents with the lowest level of education represent $43.2 \%$ of the sample, while a secondary degree is hold by $26.1 \%$ of respondents and a high school degree by $25.4 \%$ of respondents. Finally, only $5.3 \%$ of respondents have a university or higher degree.

Information on income is not directly available in the MS database. However, excellent measures of income are available in the 1999 Survey of Household Income and Wealth (SHIW) conducted by the Banca d'Italia (2000). Therefore, we use data on individual total disposable income, age, occupational status, and educational characteristics from SHIW to impute income for individuals in the MS data (details are reported in Atella and Pollastri, 2004). Finally, $20 \%$ of the households are below the poverty line which is computed as $60 \%$ of the median income.

\subsection{Exclusion restrictions}

As mentioned in Section 3.1, we use exclusion restrictions to aid identification of the causal parameters. We have identified two potential useful candidate variables for exclusion. The first one is the average number of patients per PCP in the region. This variable provides an estimate of the workload of PCP's and thus possible waiting times: higher this number, higher should be the waiting time in the PCP's office and/or waiting time for a PCP visit. We expect this variable to have a negative effect on the number of PCP visits but not to have direct effects on the numbers of public or private specialist visits. The second variable is the ratio of the total number of specialist physicians in the local area to the number of practicing specialists in that area. Some specialists are in non-practicing (bureaucratic) positions so this ratio is always greater than one: higher this number, the greater the size of the bureaucracy. We expect this ratio to have a negative impact on the number of public specialist visits, but not to have direct effects on PCPs or private specialist visits.

We recognize that the exclusion restrictions, as always, may be argued against. Therefore, we have now estimated a number of additional models, with variations in the way the two "supply" variables, patients per GP and our measure of bureaucracy, enter the simultaneous equations model. Note also that our model is theoretically identified by functional form only, a variant we have also estimated. The results of these specification checks are summarized in Table 7 and discussed in the subsection on robustness.

\section{Results}

We have estimated two types of models. First we have estimated single-equation negative binomial count regressions. These specifications for public and private specialist visits assume that any visits variables that appear as covariates in the regressions can be treated as exogenous. Estimated marginal effects of covariates for these models are reported in Table 3. Next we estimated the system of equations that treats visits variables on the right hand sides as endogenous. Estimated marginal effects of covariates from this model are reported in Table 4. Our discussion of results below is based on Tables 3 and 4, but for completeness we have reported parameter estimates from exogenous (single equation) and endogenous (system) models in Appendix 1.

The difference between the maximized log likelihood of the joint model, which allows for the endogeneity of visits, and the sum of the maximized log likelihoods from the single-equation models is 492.2. Given that the joint model has three additional parameters, this difference in log likelihoods suggests an overwhelming rejection of the "exogenous" model relative to the "endogenous" model, regardless of whether a likelihood ratio test or the more stringent Bayesian information criterion is used. 
Table 3

Marginal effects of covariates from independent models assuming exogeneity

\begin{tabular}{lrrr}
\hline Covariates & PCPs & Public specialist & Private specialist \\
\hline Fair health & $-0.082^{\mathrm{a}}(0.004)$ & $-0.038^{\mathrm{a}}(0.003)$ & $-0.047^{\mathrm{a}}(0.005)$ \\
Good health & $-0.201^{\mathrm{a}}(0.005)$ & $-0.085^{\mathrm{a}}(0.004)$ & $-0.105^{\mathrm{a}}(0.006)$ \\
Very good health & $-0.179^{\mathrm{a}}(0.003)$ & $-0.076^{\mathrm{a}}(0.002)$ & $-0.099^{\mathrm{a}}(0.003)$ \\
Disabled & $0.047^{\mathrm{a}}(0.006)$ & $0.032^{\mathrm{a}}(0.005)$ & $0.048^{\mathrm{a}}(0.008)$ \\
Exempt for health reasons & $0.075^{\mathrm{a}}(0.006)$ & $0.072^{\mathrm{a}}(0.005)$ & $0.004(0.005)$ \\
Exempt for health reasons & $0.047^{\mathrm{a}}(0.005)$ & $0.053^{\mathrm{a}}(0.005)$ & $-0.015^{\mathrm{a}}(0.005)$ \\
Gender & $0.026^{\mathrm{a}}(0.003)$ & $0.010^{\mathrm{a}}(0.002)$ & $0.042^{\mathrm{a}}(0.003)$ \\
Marital status & $0.002(0.003)$ & $0.005^{\mathrm{a}}(0.002)$ & $0.021^{\mathrm{a}}(0.003)$ \\
Level of education & $-0.014^{\mathrm{a}}(0.002)$ & $0.006^{\mathrm{a}}(0.001)$ & $0.024^{\mathrm{a}}(0.002)$ \\
Age & $-0.003(0.005)$ & $0.004(0.003)$ & $-0.003(0.005)$ \\
Age & $0.002^{\mathrm{a}}(0.000)$ & $-0.001^{\mathrm{a}}(0.000)$ & $-0.001^{\mathrm{a}}(0.000)$ \\
Household income & $-0.006(0.009)$ & $0.005(0.006)$ & $0.028^{\mathrm{a}}(0.009)$ \\
Poor household & $-0.007^{\mathrm{a}}(0.004)$ & $-0.003(0.002)$ & $-0.007^{\mathrm{b}}(0.004)$ \\
Patients per PCP & $-0.008^{\mathrm{a}}(0.004)$ & & $0.015^{\mathrm{a}}(0.001)$ \\
Primary care physician visits & & $-0.064^{\mathrm{a}}(0.013)$ & $0.010^{\mathrm{a}}(0.002)$ \\
Total/practicing specialists & & & $0.025^{\mathrm{a}}(0.003)$ \\
Public specialist visits & & & \\
\hline
\end{tabular}

Notes: Independent negative binomial regressions were estimated. In the equation for public specialists, the number of PCP visits is assumed to be exogenous. In the equation for private specialists, the numbers of PCP and public specialist visits are assumed to be exogenous. Marginal effects for each variable were calculated at the sample means of all other variables. Standard errors of the marginal effects were calculated by the delta method.

a The marginal effect is statistically significant at the $5 \%$ level.

b The marginal effect is statistically significant at the $10 \%$ level.

\subsection{The relationship between types of care}

Based on the single-equation estimates reported in Table 3, individuals with more PCP visits have significantly more public specialist and more private specialist visits. Also, persons with more public specialist visits have more private specialist visits. Taken at face value, these estimates imply that health care received from PCP's, public specialists

Table 4

Marginal effects of covariates from a simultaneous equations model

\begin{tabular}{lrrr}
\hline Covariates & PCPs & Public specialist & Private specialist \\
\hline Fair health & $-0.088^{\mathrm{a}}(0.005)$ & $-0.052^{\mathrm{a}}(0.003)$ & $-0.088^{\mathrm{a}}(0.006)$ \\
Good health & $-0.212^{\mathrm{a}}(0.009)$ & $-0.114^{\mathrm{a}}(0.006)$ & $-0.184^{\mathrm{a}}(0.013)$ \\
Very good health & $-0.183^{\mathrm{a}}(0.006)$ & $-0.090^{\mathrm{a}}(0.003)$ & $-0.147^{\mathrm{a}}(0.012)$ \\
Disabled & $0.047^{\mathrm{a}}(0.008)$ & $0.045^{\mathrm{a}}(0.008)$ & $0.088^{\mathrm{a}}(0.015)$ \\
Exempt for health reasons & $0.083^{\mathrm{a}}(0.006)$ & $0.101^{\mathrm{a}}(0.008)$ & $0.029^{\mathrm{a}}(0.007)$ \\
Exempt for health reasons & $0.055^{\mathrm{a}}(0.007)$ & $0.072^{\mathrm{a}}(0.007)$ & $-0.005(0.008)$ \\
Gender & $0.029^{\mathrm{a}}(0.004)$ & $0.014^{\mathrm{a}}(0.002)$ & $0.061^{\mathrm{a}}(0.008)$ \\
Marital status & $0.002(0.005)$ & $0.007^{\mathrm{a}}(0.003)$ & $0.029^{\mathrm{a}}(0.005)$ \\
Level of education & $-0.013^{\mathrm{a}}(0.002)$ & $0.007^{\mathrm{a}}(0.002)$ & $0.033^{\mathrm{a}}(0.006)$ \\
Age & $-0.004(0.006)$ & $0.004(0.004)$ & $-0.008(0.006)$ \\
Age & $0.002^{\mathrm{a}}(0.000)$ & $-0.001(0.000)$ & $-0.001(0.001)$ \\
Household income & $-0.006(0.012)$ & $0.003(0.008)$ & $0.033^{\mathrm{a}}(0.012)$ \\
Poor household & $-0.010^{\mathrm{a}}(0.004)$ & $-0.006^{\mathrm{a}}(0.003)$ & $-0.012^{\mathrm{a}}(0.004)$ \\
Patients per PCP & $-0.009^{\mathrm{a}}(0.003)$ & & $-0.044^{\mathrm{a}}(0.005)$ \\
Primary care physician visits & & $-0.016^{\mathrm{a}}(0.003)$ & $-0.078(0.072)$ \\
Total/practicing specialists & & & $-0.056^{\mathrm{a}}(0.008)$ \\
Public specialist visits & & & \\
\hline
\end{tabular}

Notes: A simultaneous equations system of negative binomial regressions was estimated. In the equation for public specialists, the number of PCP visits is assumed to be endogenous. In the equation for private specialists, the numbers of PCP and public specialist visits are assumed to be endogenous. Marginal effects for each variable were calculated at the sample means of all other variables. Standard errors of the marginal effects were calculated by the delta method.

a The marginal effect is statistically significant at the $5 \%$ level. 
and private specialists are complements. This finding contradicts much of the theory, but has an obvious explanation: endogeneity of visits in these single-equation estimates because of common unobserved heterogeneity.

When endogeneity of visits is taken into account, the marginal effects of PCP visits in the equation for public specialist visits is negative and statistically significant. The effects of PCP visits and public specialist visits are also negative and statistically significant in the equation for private specialist visits. These are consistent with the theory that health care received from PCP's, public specialists and private specialists are substitutes and underscore the importance of correcting for endogeneity.

For a better understanding of the magnitude of these effects, consider that the average number of visits to public specialists is 0.096 . Then the marginal effect of an additional PCP visit $(-0.016)$ is equivalent to a $16.7 \%$ decrease in the number of public specialist visits. The average number of visits to private specialists is 0.136 . Thus, the marginal effect of an additional PCP visit (-0.044) is equivalent to a $32 \%$ decrease in the number of private specialist visits and the marginal effect of an additional public specialist visit (-0.056) implies a $41 \%$ decrease in the number of private specialist visits. Clearly, each of these effect sizes is substantial. ${ }^{6}$ The effect of PCP and public specialist visits on private specialist visits are especially large, but understandable given the institutional features of the SSN. Although referrals are needed to see public specialists, visits to private specialists do not require referrals. Thus it is plausible (and consistent with casual empiricism) that many individuals see private specialists for conditions that are normally within the purview of PCP's.

The estimates for $\phi_{21}, \phi_{31}$ and $\phi_{32}$, defined in Eq. (4), are all significantly positive and imply large correlations between the unobserved latent factors of the equations. Therefore, visits to PCPs, public specialists and private specialists are all positively related to unobserved heterogeneity. The estimates imply pairwise correlations of 0.67 between the latent factors of PCP and public specialist visits, 0.69 between the latent factors of PCP and private specialist visits and 0.99 between the latent factors of public and private specialist visits. These estimates rule out the possibility that the main source of unobserved heterogeneity is a preference for public versus private sector care, or for specialist versus PCP care. Instead, it suggests that the main source of unobserved heterogeneity is a characteristic of the individual that affects all types of care in the same direction.

\subsection{Effects of exogenous covariates}

To describe the effects of other exogenous covariates, we focus on the results in Table 4. However, the point estimates and significance are generally very similar across the single equation and system models.

The coefficients on the excluded variables and their associated marginal effects are statistically significant and they have the correct signs. The greater the number of patients per PCP, the fewer the number of PCP visits. This is because patients have to wait more in the PCP offices or because PCPs provide less visits per patients for a given amount of time available. At the same time, the greater the ratio of total specialists to practicing specialists (our measure of bureaucracy), the lower the number of public specialist visits.

Each of the proxies for medical "need" (health status, disability, exemptions) have large effects on number of visits to each type of physician as compared to the "non-need" exogenous variables. Persons in good health tend to visit physicians less than patients in poor health. This is particularly true for PCPs and private specialists. Disability status increases the number of visits to any form of physician, but the marginal effect is higher for private specialists (about two times the size of the corresponding effect for public specialists and about three times the corresponding effect for PCPs). This seems to indicate that, conditional on health status, persons with disabilities are relatively more likely to seek care from private specialists. There are two possible explanations. First, it is possible that the quality of these doctors is higher compared to public specialists. Second, it is possible that these persons have a higher opportunity cost of time and so are less willing to wait to receive care. Unfortunately, we are unable to shed light on this issue given our data.

Those who are exempted from copayments for health conditions are more likely to visit physicians. This is particularly true for public specialists (the marginal effect is about two times that of private specialists). Those who are exempted from copayments for other reasons also seek more care, although in this case the coefficients are sig-

\footnotetext{
${ }^{6}$ Note that all of these estimates are quite precise. Note also that this precision cannot simply be attributed to the large sample size because the standard errors we report are adjusted for clustering at the region level (and there are only 20 such regions).
} 
nificant only for the PCP and public specialist equations. These results are coherent with the structure of the NHS system.

Women tend to visit more physicians. This is in line with a large body of literature. The marginal effect of being female is much higher for the private specialists compared to public specialists. This result could be explained by the high use of private gynaecologists compared to other specialities. ${ }^{7}$ Married people visit physicians more than others. This may be due either to more concern with respect to health problems by married people compared to single (who are the majority among non-married), or to the fact that married people on average may be older (although we have controlled for age separately).

Age has a different effect for each type of provider. It is not significant for private specialists, while it is significant for PCP and public specialists. While PCP use increases with age, specialist visits decrease with age. This finding might be because the elderly have, on average, less wealth and thus are less willing to pay specialist fees. If true, however, it suggests that the Italian health care system may not be achieving equity across the age distribution.

Persons who are more educated have fewer visits to PCPs, but have more visits to private specialists. This substitution of private specialist care for public care may be explained if educated people are more likely to recognize that private specialists offer better quality care and/or because they have higher opportunity costs of time. Again, we are unable to identify the specific reason for our finding.

Household equivalent income is positive and statistically significant only for private specialists. This result is robust across the two specifications. This is in line with our expectations given the institutional features of the Italian health care system and confirm the results in Atella et al. (2004). At the same time, households that have equivalized incomes below the poverty line have significantly fewer specialist visits, but their use of PCP's is no different from persons in households above the poverty line. Thus, although access to PCP care appears to be equitably provided, there appear to be issues of equity in provision of specialist care. Again, it is important to note that the marginal effect of poverty status for private specialists is twice that for public specialists, so that public specialist care is more equitably provided that private specialist care.

\subsection{Robustness checks}

We have noted earlier that, in part because of the narrow recall window in the survey, our measures of visits have large fractions of zeros. As the referees have emphasized, it is entirely possible that there is little information in the count values and that a model for binary access indicators may be just as informative. We find, however, that the count values (beyond zero and one) do have substantial informational content. To measure this, we first estimated truncated (at one) negative binomial regressions for each of our measures of visits. Then, we calculated the log likelihood value using the parameters from this model but assuming a "regular" negative binomial density. If values beyond one are sufficiently rare, or have sufficiently little information content, the log likelihood from this "hypothetical" model should be very similar to that from a "regular" negative binomial regression (because the parameters from the models should be very similar to each other). On the other hand, if the values greater than one are informative, the "regular" negative binomial regression should provide a substantially better fit. Such a comparison has a formal representation in Bayesian statistics. It can be thought of as a posterior odds comparison between the models assuming equal (uninformative) priors. We find substantial evidence for the latter view: differences in log likelihoods are 2731, 8260, and 630 for PCP, public specialist, and private specialists, respectively. Nevertheless, we have also estimated a trivariate probit model and find qualitatively similar results. There are significant substitution effects between PCP and specialist visits (of both types) but, unlike the model of counts, we find that the effect of at least one public specialist visit is negative but not significant in the equation for access to a private specialist. ${ }^{8}$

We also reestimate our model to ascertain the robustness of our results in three important dimensions. First, almost $13 \%$ of the sample are individuals who have some form of supplementary private health insurance. Such individuals can, in principle, bypass the public system altogether if these so wish. Although such individuals are likely to be different than those who do not hold private health insurance, we did not include an indicator for private insurance status because this variable would clearly be endogenous. Our first set of alternative estimates, reported in Table 5, are

\footnotetext{
7 The average number of specialist visits to a gynaecologist is 0.81 , second only to dentist visits (1.42).

8 These results are available from the authors upon request.
} 
Table 5

Marginal effects of covariates from a simultaneous equations model: sample of individuals without private insurance

\begin{tabular}{lrrr}
\hline Covariates & PCPs & Public specialist & Private specialist \\
\hline Fair health & $-0.090^{\mathrm{a}}(0.005)$ & $-0.051^{\mathrm{a}}(0.004)$ & $-0.084^{\mathrm{a}}(0.006)$ \\
Good health & $-0.214^{\mathrm{a}}(0.008)$ & $-0.110^{\mathrm{a}}(0.006)$ & $-0.176^{\mathrm{a}}(0.013)$ \\
Very good health & $-0.190^{\mathrm{a}}(0.006)$ & $-0.090^{\mathrm{a}}(0.004)$ & $-0.143^{\mathrm{a}}(0.012)$ \\
Disabled & $0.050^{\mathrm{a}}(0.008)$ & $0.045^{\mathrm{a}}(0.008)$ & $0.080^{\mathrm{a}}(0.013)$ \\
Exempt for health reasons & $0.085^{\mathrm{a}}(0.007)$ & $0.100^{\mathrm{a}}(0.009)$ & $0.029^{\mathrm{a}}(0.008)$ \\
Exempt for health reasons & $0.056^{\mathrm{a}}(0.007)$ & $0.073^{\mathrm{a}}(0.007)$ & $-0.002(0.007)$ \\
Gender & $0.028^{\mathrm{a}}(0.004)$ & $0.012^{\mathrm{a}}(0.002)$ & $0.059^{\mathrm{a}}(0.008)$ \\
Marital status & $0.000(0.005)$ & $0.008^{\mathrm{a}}(0.003)$ & $0.032^{\mathrm{a}}(0.006)$ \\
Level of education & $-0.013^{\mathrm{a}}(0.003)$ & $0.007^{\mathrm{a}}(0.002)$ & $0.030^{\mathrm{a}}(0.005)$ \\
Age & $-0.001(0.006)$ & $0.005(0.005)$ & $-0.018^{\mathrm{a}}(0.007)$ \\
Age & $0.002^{\mathrm{a}}(0.001)$ & $-0.001(0.000)$ & $0.000(0.001)$ \\
Household income & $-0.008(0.014)$ & $0.003(0.008)$ & $0.023^{\mathrm{b}}(0.014)$ \\
Poor household & $-0.010^{\mathrm{a}}(0.004)$ & $-0.006^{\mathrm{a}}(0.003)$ & $-0.011^{\mathrm{a}}(0.005)$ \\
Patients per PCP & $-0.014^{\mathrm{a}}(0.003)$ & $-0.014^{\mathrm{a}}(0.003)$ & $-0.034^{\mathrm{a}}(0.008)$ \\
Primary care physician visits & & $-0.073(0.075)$ & $-0.052^{\mathrm{a}}(0.007)$ \\
Total/practicing specialists & & & \\
Public specialist visits & & & \\
\hline
\end{tabular}

Notes: $N=95,461$. A simultaneous equations system of negative binomial regressions was estimated. In the equation for public specialists, the number of PCP visits is assumed to be endogenous. In the equation for private specialists, the numbers of PCP and public specialist visits are assumed to be endogenous. Marginal effects for each variable were calculated at the sample means of all other variables. Standard errors of the marginal effects were calculated by the delta method.

${ }^{a}$ The marginal effect is statistically significant at the $5 \%$ level.

b The marginal effect is statistically significant at the $10 \%$ level.

based on the sample of individuals who do not have supplementary private health insurance. The marginal effect of PCP visits in the equation for public specialist visits is virtually identical to the estimate in the baseline model. The effects of PCP visits and public specialist visits are negative in the equation for private specialist visits but the estimates are slightly smaller than those in the baseline model.

Second, we estimate a model without controlling for income and poverty status. Recall that the measures of income and poverty status are based on imputations which may affect our results. But our findings, shown in Table 6 , are robust

Table 6

Marginal effects of covariates from a simultaneous equations model: excluding income and poverty status

\begin{tabular}{lrrr}
\hline Covariates & \multicolumn{1}{c}{ PCPs } & Public specialist & Private specialist \\
\hline Fair health & $-0.088^{\mathrm{a}}(0.005)$ & $-0.052^{\mathrm{a}}(0.003)$ & $-0.087^{\mathrm{a}}(0.006)$ \\
Good health & $-0.212^{\mathrm{a}}(0.009)$ & $-0.114^{\mathrm{a}}(0.006)$ & $-0.184^{\mathrm{a}}(0.013)$ \\
Very good health & $-0.183^{\mathrm{a}}(0.006)$ & $-0.090^{\mathrm{a}}(0.003)$ & $-0.147^{\mathrm{a}}(0.012)$ \\
Disabled & $0.047^{\mathrm{a}}(0.008)$ & $0.045^{\mathrm{a}}(0.008)$ & $0.088^{\mathrm{a}}(0.015)$ \\
Exempt for health reasons & $0.083^{\mathrm{a}}(0.006)$ & $0.101^{\mathrm{a}}(0.008)$ & $0.029^{\mathrm{a}}(0.007)$ \\
Exempt for health reasons & $0.054^{\mathrm{a}}(0.007)$ & $0.071^{\mathrm{a}}(0.007)$ & $-0.006(0.008)$ \\
Gender & $0.028^{\mathrm{a}}(0.004)$ & $0.013^{\mathrm{a}}(0.002)$ & $0.059^{\mathrm{a}}(0.008)$ \\
Marital status & $0.002(0.005)$ & $0.008^{\mathrm{a}}(0.003)$ & $0.030^{\mathrm{a}}(0.005)$ \\
Level of education & $-0.013^{\mathrm{a}}(0.002)$ & $0.008^{\mathrm{a}}(0.002)$ & $0.036^{\mathrm{a}}(0.006)$ \\
Age & $-0.004(0.006)$ & $0.004(0.004)$ & $-0.007(0.006)$ \\
Age & $0.002^{\mathrm{a}}(0.000)$ & $-0.001(0.000)$ & $-0.001(0.001)$ \\
Patients per PCP & $-0.009^{\mathrm{a}}(0.003)$ & $-0.016^{\mathrm{a}}(0.003)$ & $-0.044^{\mathrm{a}}(0.005)$ \\
Primary care physician visits & & $-0.080(0.072)$ & $-0.056^{\mathrm{a}}(0.007)$ \\
Total/practicing specialists & & & \\
Public specialist visits & & &
\end{tabular}

Notes: A simultaneous equations system of negative binomial regressions was estimated. In the equation for public specialists, the number of PCP visits is assumed to be endogenous. In the equation for private specialists, the numbers of PCP and public specialist visits are assumed to be endogenous. Marginal effects for each variable were calculated at the sample means of all other variables. Standard errors of the marginal effects were calculated by the delta method.

${ }^{\text {a }}$ The marginal effect is statistically significant at the 5\% level. 
Table 7

Robustness check results—marginal effects

\begin{tabular}{|c|c|c|c|}
\hline Models & $\begin{array}{l}\text { GP visit effect in public } \\
\text { specialist equation }\end{array}$ & $\begin{array}{l}\text { GP visit effect in private } \\
\text { specialist equation }\end{array}$ & $\begin{array}{l}\text { Public specialist effect in } \\
\text { private specialist equation }\end{array}$ \\
\hline $\begin{array}{l}\text { Model 1-baseline } \\
\text { Single equation } \\
\text { System }\end{array}$ & $\begin{array}{r}0.015^{\mathrm{a}}(0.001) \\
-0.016^{\mathrm{a}}(0.003)\end{array}$ & $\begin{array}{r}0.010^{\mathrm{a}}(0.002) \\
-0.044^{\mathrm{a}}(0.005)\end{array}$ & $\begin{array}{r}0.025^{\mathrm{a}}(0.008) \\
-0.056^{\mathrm{a}}(0.008)\end{array}$ \\
\hline $\begin{array}{l}\text { Model } 2 \\
\text { Single equation } \\
\text { System }\end{array}$ & $\begin{array}{r}0.015^{\mathrm{a}}(0.001) \\
-0.016^{\mathrm{a}}(0.003)\end{array}$ & $\begin{array}{r}0.010^{\mathrm{a}}(0.002) \\
-0.044^{\mathrm{a}}(0.005)\end{array}$ & $\begin{array}{r}0.025^{\mathrm{a}}(0.003) \\
-0.056^{\mathrm{a}}(0.008)\end{array}$ \\
\hline $\begin{array}{l}\text { Model } 3 \\
\text { Single equation } \\
\text { System }\end{array}$ & $\begin{array}{r}0.015^{\mathrm{a}}(0.001) \\
-0.016^{\mathrm{a}}(0.003)\end{array}$ & $\begin{array}{r}0.010^{\mathrm{a}}(0.002) \\
-0.044^{\mathrm{a}}(0.005)\end{array}$ & $\begin{array}{r}0.025^{\mathrm{a}}(0.003) \\
-0.056^{\mathrm{a}}(0.007)\end{array}$ \\
\hline $\begin{array}{l}\text { Model } 4 \\
\text { Single equation } \\
\text { System }\end{array}$ & $\begin{array}{r}0.015^{\mathrm{a}}(0.001) \\
-0.016^{\mathrm{a}}(0.003)\end{array}$ & $\begin{array}{r}0.010^{\mathrm{a}}(0.002) \\
-0.044^{\mathrm{a}}(0.005)\end{array}$ & $\begin{array}{r}0.025^{\mathrm{a}}(0.003) \\
-0.056^{\mathrm{a}}(0.008)\end{array}$ \\
\hline $\begin{array}{l}\text { Model } 5 \\
\text { Single equation } \\
\text { System }\end{array}$ & $\begin{array}{r}0.015^{\mathrm{a}}(0.001) \\
-0.016^{\mathrm{a}}(0.003)\end{array}$ & $\begin{array}{r}0.010^{\mathrm{a}}(0.002) \\
-0.044^{\mathrm{a}}(0.005)\end{array}$ & $\begin{array}{r}0.025^{\mathrm{a}}(0.003) \\
-0.056^{\mathrm{a}}(0.007)\end{array}$ \\
\hline
\end{tabular}

Notes: Simultaneous equation systems of negative binomial regressions were estimated. In model 2 population was included in all equations; in model 3 bureaucracy was included in GP equation and number of patients per GP in public specialist equation; in model 4 population was added in all equations and patients per public specialist in public specialist equation; in model 5 population at regional level was included in all equations and the number of patients per public specialists was added in both specialist equations. Marginal effects for each variable were calculated at the sample means of all other variables. Standard errors of the marginal effects were calculated by the delta method.

a The marginal effect is statistically significant at the $5 \%$ level.

to dropping these variables from our set of covariates; the parameter estimates do change somewhat (not shown) but the marginal effects are virtually the same.

Finally, we have estimated a number of additional variations on our preferred model that speak to the issue of the quality of our exclusion restrictions. ${ }^{9}$ First, one might argue that we have failed to condition on population, which may affect the interpretation and our claims of exogeneity of the excluded variables. The key coefficients from this model are shown in Table 7. Of importance are the observations that the coefficients on the endogenous regressors do not change much, and that population at regional level is insignificant in all three equations. In the second specification, we include the measure of bureaucracy in the PCP equation and PCP density in the public specialist equation. Again, the results reported in Table 7 show that the coefficients on the endogenous regressors change only very slightly relative to the baseline. We have also created a variable to measure public specialist density. Although it might be desirable, we are unable to calculate private specialist density because counts of private specialists are not available. We have incorporated public specialist density in two specifications. In the first, it is only included in the public specialists equation. In the second, it is included in both specialist equations. The results are not substantially changed. Consequently, it appears that the results are quite robust to these changes in specification.

\section{Conclusions}

In this paper, we have developed an econometric model to investigate whether visits to PCPs, public sector specialists and private sector specialists are substitutes or complements in a mixed public-private system. Our model allows for the endogeneity and discreteness of measures of utilization and estimated this model using maximum simulated likelihood. We have found that, once common unobserved heterogeneity is properly accounted for, PCPs, public specialists and private specialists are substitute sources of medical care. We find substantial evidence of endogeneity and that unobserved heterogeneity is positively correlated across physician types. We are able to rule out the possibility that the main source of unobserved heterogeneity arises either from a preference for the private or public sector, or from

\footnotetext{
${ }^{9}$ We thank two anonymous referees for raising these issues.
} 
a preference for PCP versus specialist care. Instead, it appears that the main source of unobserved heterogeneity is an individual characteristic that increases or decreases the number of all types of visits simultaneously. Health shocks are a source of such a characteristic.

Based on our results, in a mixed system of health care provision, PCPs have a gatekeeping role not only to care from public specialists, which is mandated by the public system, but also to care from private specialists because they are substitutes. Public and private specialists are also substitutes. Thus, if either the cost of care (monetary and time) from public specialists is sufficiently high or the quality of public specialists sufficiently low, individuals would opt for care from private specialists rather than public ones. To the extent that an increase in the use of private services may be accompanied by a decrease in the willingness to pay taxes for the public sector, thus undermining quality in the public sector, pricing and quality of care in the public sector have implications for its viability.

\section{Appendix A. Parameter estimates}

\begin{tabular}{|c|c|c|c|c|}
\hline \multirow[t]{2}{*}{ Variables } & \multicolumn{2}{|c|}{ Independent NB2 } & \multicolumn{2}{|l|}{ Joint NB2 } \\
\hline & Coefficient & $t$-Statistics & Coefficient & $t$-Statistics \\
\hline \multicolumn{5}{|l|}{ Primary care physician equation } \\
\hline Fair health & -0.509 & -21.000 & -0.540 & -21.456 \\
\hline Good health & -1.205 & -39.324 & -1.255 & -40.577 \\
\hline Very good health & -1.764 & -35.180 & -1.816 & -36.517 \\
\hline Disabled & 0.247 & 9.077 & 0.249 & 8.916 \\
\hline Exempt for health reasons & 0.373 & 15.420 & 0.405 & 16.389 \\
\hline Exempt for other reasons & 0.247 & 9.946 & 0.280 & 10.985 \\
\hline Gender & 0.151 & 8.834 & 0.168 & 9.679 \\
\hline Marital status & 0.012 & 0.597 & 0.009 & 0.468 \\
\hline Level of education & -0.082 & -7.204 & -0.072 & -6.300 \\
\hline Age & -0.018 & -0.648 & -0.027 & -0.956 \\
\hline $\mathrm{Age}^{2}$ & 0.012 & 4.522 & 0.013 & 5.131 \\
\hline Household income & -0.034 & -0.641 & -0.019 & -0.352 \\
\hline Poor household & -0.043 & -1.929 & -0.054 & -2.389 \\
\hline Patients per PCP & -0.046 & -1.879 & -0.054 & -2.261 \\
\hline$\alpha$ & 1.921 & 44.096 & 0.504 & 16.087 \\
\hline \multicolumn{5}{|l|}{ Public specialist equation } \\
\hline Primary care physician visits & 0.201 & 12.607 & -0.132 & -4.227 \\
\hline Fair health & -0.538 & -12.823 & -0.675 & -15.345 \\
\hline Good health & -1.169 & -23.004 & -1.399 & -26.366 \\
\hline Very good health & -1.696 & -21.588 & -1.952 & -24.596 \\
\hline Disabled & 0.366 & 8.098 & 0.450 & 9.654 \\
\hline Exempt for health reasons & 0.708 & 17.794 & 0.856 & 21.012 \\
\hline Exempt for other reasons & 0.558 & 13.169 & 0.663 & 15.449 \\
\hline Gender & 0.128 & 4.526 & 0.164 & 5.892 \\
\hline Married & 0.068 & 2.045 & 0.081 & 2.496 \\
\hline Level of education & 0.086 & 4.791 & 0.094 & 5.249 \\
\hline Age & 0.056 & 1.211 & 0.068 & 1.502 \\
\hline $\operatorname{Age}^{2}$ & -0.009 & -1.980 & -0.009 & -2.101 \\
\hline Household income & 0.068 & 0.819 & 0.050 & 0.617 \\
\hline Poor household & -0.046 & -1.264 & -0.065 & -1.823 \\
\hline Total/practicing specialists & -0.855 & -4.139 & -0.836 & -4.122 \\
\hline$\alpha$ & 5.252 & 29.874 & 1.663 & 12.260 \\
\hline \multicolumn{5}{|l|}{ Private specialist equation } \\
\hline Primary care physician visits & 0.079 & 4.483 & -0.413 & -9.771 \\
\hline Public specialist visits & 0.205 & 11.261 & -0.197 & -4.386 \\
\hline Fair health & -0.398 & -9.071 & -0.674 & -14.472 \\
\hline Good health & -0.873 & -17.393 & -1.329 & -24.138 \\
\hline Very good health & -1.177 & -17.967 & -1.745 & -25.443 \\
\hline Disabled & 0.335 & 6.991 & 0.489 & 9.921 \\
\hline Exempt for health reasons & 0.030 & 0.688 & 0.175 & 3.996 \\
\hline
\end{tabular}


Appendix 1 (Continued)

\begin{tabular}{|c|c|c|c|c|}
\hline \multirow[t]{2}{*}{ Variables } & \multicolumn{2}{|c|}{ Independent NB2 } & \multicolumn{2}{|l|}{ Joint NB2 } \\
\hline & Coefficient & $t$-Statistics & Coefficient & $t$-Statistics \\
\hline Exempt for other reasons & -0.125 & -2.660 & -0.044 & -0.938 \\
\hline Gender & 0.340 & 13.548 & 0.426 & 16.741 \\
\hline Marital status & 0.172 & 5.653 & 0.196 & 6.513 \\
\hline Level of education & 0.194 & 12.568 & 0.228 & 14.768 \\
\hline Age & -0.020 & -0.475 & -0.048 & -1.161 \\
\hline $\mathrm{Age}^{2}$ & -0.009 & -2.225 & -0.005 & -1.161 \\
\hline Household income & 0.227 & 3.040 & 0.236 & 3.272 \\
\hline Poor household & -0.055 & -1.624 & -0.072 & -2.138 \\
\hline$\alpha$ & 6.281 & 41.375 & 2.657 & 13.454 \\
\hline \multirow[t]{2}{*}{ Variables } & \multicolumn{2}{|l|}{ Independent NB2 } & \multicolumn{2}{|l|}{ Factor loadings } \\
\hline & Coefficient & $t$-Statistics & Coefficient & $t$-Statistics \\
\hline$\phi_{21}$ & & & 0.774 & 12.98 \\
\hline$\phi_{31}$ & & & 1.142 & 16.79 \\
\hline$\phi_{32}$ & & & 0.385 & 3.160 \\
\hline Log likelihood & \multicolumn{2}{|c|}{$-132,472$} & \multicolumn{2}{|c|}{$-132,068$} \\
\hline
\end{tabular}

Notes: Estimates for intercepts are not reported. The parameters $\phi_{21}, \phi_{31}$ and $\phi_{32}$ are defined in Eq. (4). The log likelihood for the independent NB2 model is the sum of three independent, univariate NB2 regressions.

\section{References}

Amemiya, T., 1974. The nonlinear two-stage least-squares estimator. Journal of Econometrics 2, 105-110.

Atella, V., Brindisi, F., Deb, P., Rosati, F.C., 2004. Determinants of access to physician services in Italy: a latent class probit approach. Health Economics 13, 657-668.

Atella, V., Pollastri, C., 2004. Income Variables Matching Between Bank of Italy "Survey on Household Income and Wealth" and ISTAT "Indagine Multiscopo sulle Famiglie". Mimeo.

Banca d'Italia, 2000. Indagine sui redditi delle famiglie. Banca d'Italia, Roma.

Besley, T., Coate, S., 1991. Public provision of private goods and the redistribution of income. American Economic Review 81, $979-984$.

Besley, T., Hall, J., Preston, I., 1999. The demand for private health insurance: do waiting lists matter? Journal of Public Economics 72, 155181.

Bhat, C.R., 2001. Quasi-random maximum simulated likelihood estimation of the mixed multinomial logit model. Transportation Research: Part B 35, 677-693.

Cameron, A.C., Trivedi, P.K., 1998. Regression Analysis of Count Data. Econometric Society Monograph. Cambridge University Press, New York.

Chib, S., Winkelmann, R., 2001. Markov chain Monte Carlo analysis of correlated count data. Journal of Business and Economic Statistics 19, 428-435.

Cullis, J.G., Jones, P.R., 1985. National health service waiting list: a discussion of competing explanations and a policy proposal. Journal of Health Economics 4, 119-135.

Cutler, D., Gruber, J., 1996. The effect of Medicaid expansions on public insurance, private insurance and redistributions. American Economic Review 86, 378-383.

Deb, P., Trivedi, P.K., 2006. Specification and simulated likelihood estimation of a non-normal treatment-outcome model with selection: application to health care utilization. Econometrics Journal 9, 307-331.

Epple, D., Romano, R., 1996. Public provision of private goods. Journal of Political Economy 104, 57-84.

Fabbri, D., Monfardini, C., 2002. Public versus private health care services demand in Italy. Working Paper.

Gouriéroux, C., Monfort, A., 1996. Simulation Based Econometrics Methods. Oxford University Press, New York.

Gouveia, M., 1996. Majority rule and the public provision of health care. Public Choice 93, 221-244.

Greene, W.H., 2003. Econometric Analysis. Prentice Hall, New Jersey.

Gurmu, S., Elder, J., 2000. Generalized bivariate count data regression models. Economics Letters 68, 31-36.

Ireland, N., 1990. The mix of social and private provision of goods and services. Journal of Public Economics 43, 201-219.

ISTAT, 2001. Condizioni di salute e ricorso ai servizi sanitari. In: Indagine Multiscopo sulle Famiglie_Anni 1999-2000. ISTAT.

Jung, R.C., Winkelmann, R., 1993. Two aspects of labor mobility: a bivariate Poisson regression approach. Empirical Economics 18, 543556.

Martin, S., Smith, P., 1998. Modelling waiting times for elective surgery. Journal of Public Economics 71, 141-164.

McFadden, D., Train, K., 2000. Mixed MNL models for discrete response. Journal of Applied Econometrics 15, 447-470. 
Munkin, M., Trivedi, P.K., 1999. Simulated maximum likelihood estimation of multivariate mixed-Poisson regression models, with application. Econometrics Journal 2, 29-48.

Propper, C., 2000. The demand for private health care in UK. Journal of Health Economics 19, 855-876.

Stiglitz, J.E., 1974. The demand for education in public and private school systems. Journal of Public Economics 3, 349-385.

Train, K., 2003. Discrete Choice Methods with Simulation. Cambridge University Press, New York.

Windmeijer, F.A.G., Santos Silva, J.M.C., 1997. Endogeneity in count data models: an application to demand for health care. Journal of Applied Econometrics 12, 281-294. 